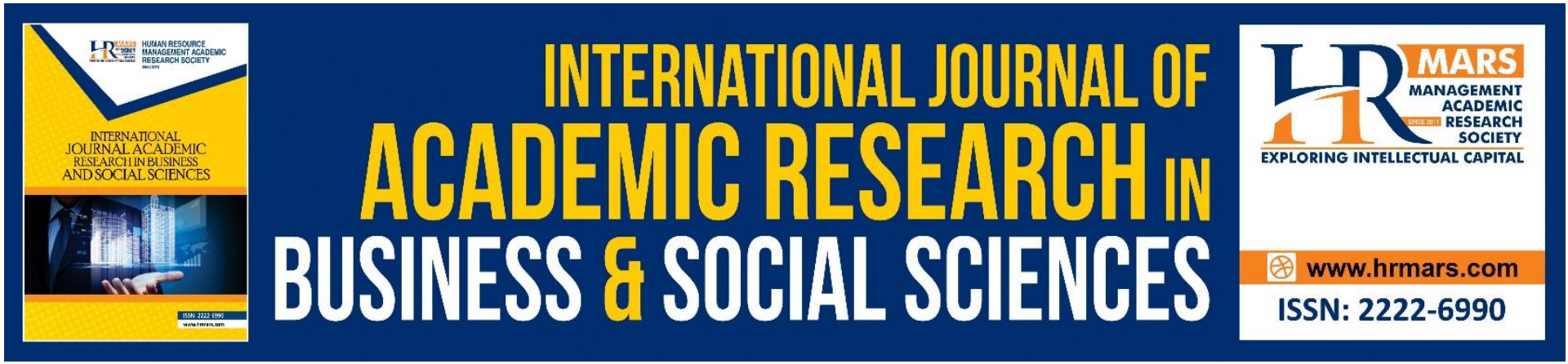

\title{
The Application of Solo Taxonomy in Writing Module Based on Self and Peer Assessment for Primary Level in Malaysia: A Pilot Study
}

Norhafilah Abdullah, Md. Nasir Masran

To Link this Article: http://dx.doi.org/10.6007/IJARBSS/v11-i6/10109

DOI:10.6007/IJARBSS/v11-i6/10109

Received: 01 April 2021, Revised: 28 April 2021, Accepted: 16 May 2021

Published Online: 07 June 2021

In-Text Citation: (Abdullah \& Masran, 2021)

To Cite this Article: Abdullah, N., \& Masran, M. N. (2021). The Application of Solo Taxonomy in Writing Module Based on Self and Peer Assessment for Primary Level in Malaysia: A Pilot Study. International Journal of Academic Research in Business and Social Sciences, 11(6), 186-195.

Copyright: (c) 2021 The Author(s)

Published by Human Resource Management Academic Research Society (www.hrmars.com)

This article is published under the Creative Commons Attribution (CC BY 4.0) license. Anyone may reproduce, distribute, translate and create derivative works of this article (for both commercial and non-commercial purposes), subject to full attribution to the original publication and authors. The full terms of this license may be seen at: $\underline{\text { http://creativecommons.org/licences/by/4.0/legalcode }}$

Vol. 11, No. 6, 2021, Pg. 186 - 195

http://hrmars.com/index.php/pages/detail/IJARBSS

JOURNAL HOMEPAGE

Full Terms \& Conditions of access and use can be found at http://hrmars.com/index.php/pages/detail/publication-ethics 


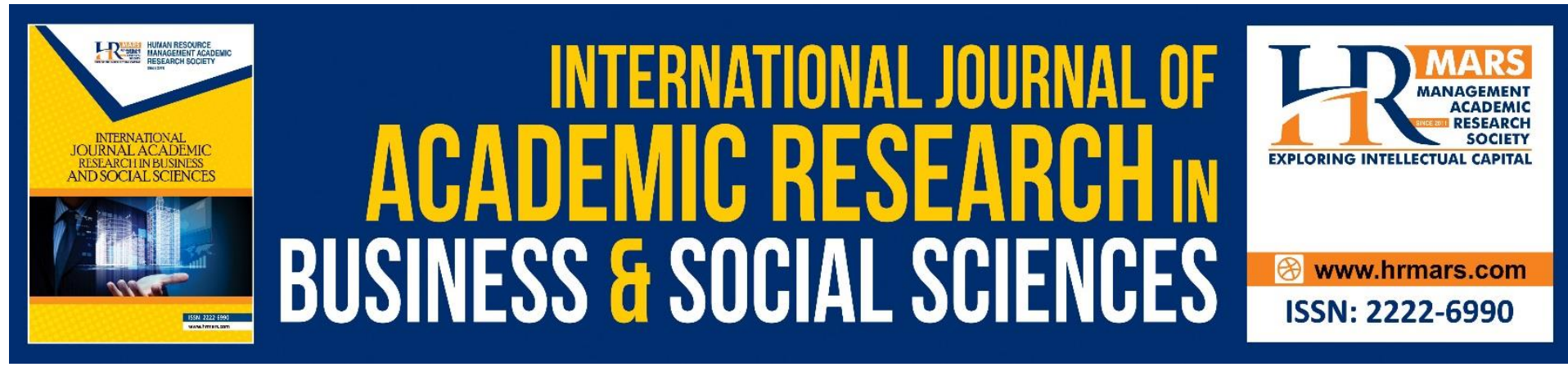

\title{
The Application of Solo Taxonomy in Writing Module Based on Self and Peer Assessment for Primary Level in Malaysia: A Pilot Study
}

\author{
Norhafilah Abdullah, Md. Nasir Masran \\ Faculty of Human Science, Universiti Pendidikan Sultan Idris, Malaysia
}

\begin{abstract}
Students need to know their current levels of thinking and how to progress to the next level by self-assess themselves. Otherwise, they would constantly demand teachers to spoon-feed them to achieve a specific level. This is due to the students' failure to master the lower order thinking skills level that hinder them from making systematic and strategic progress in their learning. The aim of this study was to evaluate a feedback of writing module based on SOLO taxonomy which apply self and peer assessment in their construction of writing development. To test the reliability of the module, a pilot study for the implementation of the module was conducted with the help of the English Language teacher who teach the remedial class in the selected school. The purpose of this pilot study is for ensuring the suitability of the module in terms of time allocation, clarity of instruction, suitability distribution of sub modules and organized activities. A total of 30 Year 5 low achiever learners (LAL) in a primary school have been selected for the pilot study. A set of questionnaires with five constructs consisting of 20 items has been distributed and the means score showed significant accuracy. The item verification process based on the agreement of seven experts using the Content Validity Index (CVI) approach received experts $(n=7)$ consensus reliability value $(\alpha)=0.92$. The results indicated that the LAL can adapt the self and peer assessment approach based on SOLO taxonomy in a short time and proves that the self- peer assessment process can be taught to the low achiever primary level if supported by opportunities to practice it regularly in an organized and supportive classroom environment.
\end{abstract}

Keywords: Self and Peer Assessment, Self-Regulated Learning, Solo Taxonomy, Writing Development, Low Proficiency

\section{Introduction}

Recent changes in Malaysia education have witnessed a new scenario in the methodology of teaching and learning. Primary schools in Malaysia are also undergoing fundamental changes in the curriculum and the teaching and learning processes due to the government's effort in reviewing and upgrading the education system in our country. The implementation of the Malaysian Education Blueprint Plan 2013-2025 (MEBP) stresses on student- centered approaches and holistic development of the individuals. In line with the objective of the Ministry of Education (MOE) to fulfil the vision of MEBP, teachers were encouraged to apply 
the $21^{\text {st }}$ century teaching and learning pedagogy during their lesson. Thus, the teaching practice and approach need to be evolved to align with the changes.

A shift from teacher-centered to learner-centered implied assessment as essential part of the learning process and has to be integrated in the task or activities during the lesson. The learner centered approach includes active learning, cooperative learning and inductive learning. Teachers' role is as facilitator who create a context to motivate the learner by providing content and resources as well as organizing constructivist learning activities (Schreurs \& Dumbraveanu, 2014). Introducing peer and self- assessment approaches into English teaching may be quite challenging but beneficial to strengthening the relationship between teacher feedback and students learning, encouraging student to change the way of learning and promote lifelong learning. Vygotsky's theory indicated that the ability of the young learner to make meaning will be better if they are able to work in an atmosphere where they can interact with their teacher and classmate before going to their writing alone. The experience and criticism make they become more aware of themselves (Wertsch, 1985).

However, in the study of the concern of EL teachers towards School Based Assessment (SBA) conducted by Majid (2011) has found out that although the teacher has awareness of the SBA implementation but their knowledge and skills in implementing SBA is still quite poor despite of the guidelines and objectives provided by the ministry. Hence, she suggested frequent training focusing on time management, students' exposure to assessment and techniques or strategies should be done and helpful. Another study by Sardareh (2018) indicated that using feedback systematically to support learning is intermittent and teachers are not aware of strategies to implement formative feedback effectively to enhance students' learning and use the information in their future instruction. Therefore, the researcher felt that there is an urge to fulfill the gap in preparing teaching and learning material based on assessment pedagogy approach. For now, there is no specific module in current market focusing in self-assessment and peer feedback to enhance writing proficiency in Malaysian context for teachers' guidance. The proposed module, Collaborative-Student Takes Assessment Responsibility (Co-STAR) module was intended as an example in proposing how collaborative self-assessment and peer feedback approach could be incorporated in formal learning to assist the low achievers in English Language. The GALUS (gagal lulus) and GARUK (gagal teruk) students will work collaboratively with their peers through a few sets of exercises developed based on SOLO taxonomy and writing skills in the MOE syllabus.

\section{Literature Review}

The Framework of Observed Learning Outcomes (SOLO) is a cognitive processing taxonomy developed in the 1970s by John Biggs and Kevin Collis. Structure of the Observed Learning Outcome (SOLO) taxonomy categorizes mental function by means of observable quantities and quality of tasks undertaken or items created by students as a means of enhancing the quality of examinations and is used in examinations in some countries, particularly Australia and New Zealand (Kayani, Ajmal, \& Rahman, 2010).

There are some benefits of the SOLO framework over the Bloom taxonomy in the measurement of student learning. These benefits are not only related to item construction and grades, but also include aspects of the assessment process that pay attention to how students think, and how teachers formulate teaching procedures to help students use increasingly more complicated cognitive processes. In 2013, Professor John Hattie identified SOLO as "the most powerful model for understanding and integrating these levels into 
learning intentions and success criteria." Teachers have discovered that using SOLO in the classroom is an effective strategy because it allows students to see that their academic outcomes are related to their actions and methods, rather than to chance or predetermined skills.

In comparison to the Bloom taxonomy, which appears to be used more by teachers than by students, SOLO taxonomy can be taught to students in such a way that they can learn to write significantly more difficult answers or prompts. There is a closer parallel between how teachers teach and how students learn. Teachers and students frequently switch from more surfaces to deeper structures, and this is expressed in four levels. The levels should be viewed in relation to the abilities of the students. Six-year-old students will be taught to derive basic concepts and propose ideas, albeit evidently at a different degree of abstraction and description than their older peers. Using the SOLO approach, it is reasonably straightforward to create objects to test certain abstractions.

Not only does the SOLO taxonomy indicate an aspect writing approach, but the same taxonomy may be used to score items. Each answer is measured by the marker to evaluate either the number of ideas or the scale of interrelation (directly related or abstracted to more general principles). This could contribute to better scoring reliability. Using SOLO taxonomy really enables teachers and students the chance to go further into learning and analyse learning as they move through the learning process, regardless of the topic or subject they are interested with. By reading blogs and study, one of the beneficial benefits of SOLO is that it makes it easy for teachers to recognize the stages and thus helps guide students through the process (Hattie, 2008). The SOLO Taxonomy proponent has delved deeper to a simpler way for students to comprehend that grants them the ability to measure their own learning. Hattie proposes that instructors should willing to use:

- No Idea - equivalent to the prestructural level.

- One Idea - equivalent to the unistructural level

- Many Ideas - equivalent to the multistructural level

- Relate - equivalent to the relational level

- Extend - equivalent to the extended abstract

Teachers commonly use SOLO Taxonomy to establish learning outcomes, interactions and assessments at various levels that help them to evaluate and control their teaching practice (Mahmood, Ali \& Hussain, 2014). Thompson (2007) claimed that the SOLO taxonomy offers a structure for measuring the consistency of answers and self-learning expectations that students can meet in order to be at specific stages of learning. Hook and Mills (2011) concluded that teachers and students are systematically supported by the SOLO taxonomy to grasp the learning process and learning performance.

SOLO Taxonomy has also been used in evaluations to measure the consistency of responses of learners, set standards of questions and create learning outcomes (Teaching and Educational Development Institute, 2015; Groth, 2003). As a result of the general interest of Asian countries and UNICEF, the East Asia Learning Achievement Report, also known as EALAS, was launched in Asia to introduce a collaborative strategic activity to evaluate learner achievement in the region. In order to describe a student's comprehension of a topic at growing degrees of difficulty, EALAS incorporated the SOLO taxonomy. Some of the selected schools in nine Asian countries: Mongolia, China, South Korea, Vietnam, Myanmar, Indonesia, the Philippines, Timor-Leste and the Pacific have successfully carried the pilot studies. (UNICEF, 2007). 
A new evaluation system based on SOLO taxonomy was implemented in the province of Punjab, Pakistan, in 2005 to specifically evaluate the consistency of the test system, requiring teachers to have adequate knowledge of SOLO taxonomy in order to incorporate the taxonomy into their teaching methods and assessment methods (Mahmood, Ali \& Hussain, 2014). In 2007, all universities in Denmark were required to reformulate their curriculum in which the emphasis on students' achievement is their ability in accomplishing explicit course objectives and some universities used SOLO taxonomy as the criteria for the systematic reformulation of their learning outcomes (Brabrand \& Dahl, 2009). In order to empower learners to be autonomous learners and think critically, New Zealand schools have introduced SOLO taxonomy into their curricula and pedagogies. (Hook \& Mills, 2012).

In Malaysian studies in which SOLO is used to construct test items for pencil-and-paper tests and interviews in which thought is classified according to SOLO standards, SOLO taxonomy is often used in evaluating the comprehension and thinking capacity of students (Lian, Yew \& Meng, 2009; Lian \& Yew, 2012; Nora \& Idris, 2010). A research by Idek, M. S. B. (2020) to address the potential use of SOLO taxonomy as a model for the construction of questions in ESL reading comprehension specified the techniques in designing questions enable students to move from lower level of understanding to higher level of thinking and there is also a need to generate cognitive conflict, which stimulates students to consider more alternatives while formulating their opinions based on knowledge gleaned from reading materials provided to them. It is clearly apparent that SOLO taxonomy has been used rigorously in assessments to evaluate the level of thought processes as well as in curriculum content to measure academic achievements. This implies that critical thinking based on SOLO taxonomy can guide students in developing their thinking pattern and this can possibly be realized through its application as a questioning technique.

There were studies that showed the feasibility of SOLO taxonomy to be used in language learning especially in English language teaching. Campbell, Smith, Brooker (1998) concluded that SOLO taxonomy could enhance students' abilities to write essays by creating specific objectives based on the SOLO structure. A research undertaken by Solomon (2013) to identify the impact of teaching on the scholarly writing of graduate students of ESL in the Philippine Institute. SOLO taxonomy was used to test the students' essays, which involved the evaluation of their reading comprehension, writing and grammar before and after the experiment. The students were found to have a poor degree of basic reading and reading comprehension.

In another analysis on the use of SOLO taxonomy in ESL writing, it was discovered that students need to know their current level of thought and the difference in their thinking skills and how to step on to the next level, otherwise they will continuously ask teachers to feed them to a specific level. This is attributed to students' inability to master lower-level thought skills, which hinders them from making systematic and strategic progress in their learning (Hyland, 2010). Chan, Tsui, Chan and Hong (2002) studied the implementation of SOLO taxonomy as an ESL grading system to 28 students at Hong Kong Polytechnic University. They found that several teachers felt that SOLO could be used extensively to test the mastery of material and language skills in ESL classes.

The use of SOLO taxonomy in ESL learning has been discussed in many articles. Chan, Tsui, Chan and Hong (2002) examined the usage of SOLO taxonomy by Hong Kong Polytechnic teachers for the evaluation and graduation of student assignments in the field of ESL. The findings of the instructor interviews indicate that there was good feedback on its implementation with a small need for change. Solomon (2004) analyzed the impact of 
teaching on the writing of ESL students in a tertiary level of education in the Philippines using SOLO taxonomy and exposed the lack of critical reading skills and low reading comprehension skill among students.

Freij and Ahlin (2014) investigated the role of the SOLO level in the ability of students to acknowledge their level of proficiency in ESL writing. The results revealed that students who did not grasp the lower level of SOLO taxonomy were unable to recognize the difference in their comprehension and continuously relied on input from teachers. Students need to be able to differentiate between lower and higher levels of SOLO in order to define their existing levels and how to transition from that level to the next level. These studies suggest that the role of SOLO taxonomy in ESL learning has been explored, but the emphasis has been limited to its role in ESL writing, and SOLO taxonomy has only been used for evaluation and input. The purpose of this study is therefore to explore the role of SOLO taxonomy in ESL writing, in order to encourage students' development of thought skills that go beyond simple understanding of higher order thinking.

\section{Methodology}

Co-STAR Module proposes a module on how students can work collaboratively with their peer through a structured self-assessment and peer feedback practice. It could be incorporated in formal learning to assist the low achievers in English Language. The excellent and moderate students will work cooperatively with colleagues through a few sets of exercises developed based on SOLO taxonomy and writing skills in MOE English syllabus for Year 5. Qualitative and quantitative data were involved in the phase of need analysis and design of the module development.

\section{Module Development}

This study employs a module development design based on the Sidek's Module Development Model (Noah \& Ahmad, 2005). This model comprises of two phases: Phase I and II each with different purposes. The first three steps are the design of the module development and evaluation which begin with the problem awareness based on the researcher's experience, literature review and preliminary study. The existing knowledge and the findings of the survey were used to provide important criteria to be included in designing and developing the CoSTAR module. After the draft of the module has been completed, researcher will proceed to the next step; the evaluation of validity, reliability and effectiveness. To test the reliability of the module, a pilot study for the implementation of the module was conducted with the help of the English Language teacher who teach the remedial class in the selected school. The purpose of this pilot study is for ensuring the suitability of the module in terms of time allocation, clarity of instruction, suitability distribution of sub modules and organized activities. If it is proven that this module has high credibility and reliability then it can be considered as a complete module and is ready to be used.

\section{Module Design}

The conceptual model of self-regulation by Butler and Winne (1995) underlying the development of the Co-STAR module which emphasized the internal and external outcomes of the self and peer assessment practice. Researcher believes through systematic learning activities and assessment proposed in the module would help the LAL to improve their essay writing thus achieve better grade. Besides, it also triggered positive motivation and selfesteem which encourage independent and self -regulated learning in future. In addition, the 
format of each items in the module were constructed based on five level proponents of SOLO taxonomy.

The format of this module consists four range of levels from beginner to advance in order to help the students' progress in their essay writing. The writing editing checklist is a guideline and as a tool for the student and peer to assess their writing product. The progress tracker column is set out as an explicit motivation goals for the student's self-evaluation. It is also as a resource for the teachers to track their student's understanding and gear their lesson based upon this information.

Table 1. Brief Outline of the Co-STAR Module

\begin{tabular}{|c|c|c|c|c|}
\hline Solo Tax. Level & $\begin{array}{l}\text { Levels of } \\
\text { Module }\end{array}$ & $\begin{array}{l}\text { Learning } \\
\text { intension of } \\
\text { Writing Skills }\end{array}$ & $\begin{array}{l}\text { Writing Editing } \\
\text { Checklist } \\
\text { (Rubric) }\end{array}$ & $\begin{array}{l}\text { Progress } \\
\text { Tracker }\end{array}$ \\
\hline \multirow{2}{*}{ Extend } & \multirow{2}{*}{ Advanced } & \multirow{2}{*}{$\begin{array}{l}\text { Create } \\
\text { Evaluate, } \\
\text { Formulate } \\
\text { Generate } \\
\text { Reflect } \\
\text { Predict }\end{array}$} & \multirow{2}{*}{10 stars writing } & Level 4 \\
\hline & & & & $\begin{array}{l}\text { I can teach } \\
\text { someone else } \\
\text { how to do it. }\end{array}$ \\
\hline \multirow[t]{3}{*}{ - Relate } & \multirow{3}{*}{ Intermediate } & \multirow{3}{*}{$\begin{array}{l}\text { Analyze } \\
\text { Relate } \\
\text { Apply } \\
\text { Compare and } \\
\text { contrast }\end{array}$} & \multirow{3}{*}{7 stars writing } & Level 3 \\
\hline & & & & \\
\hline & & & & $\begin{array}{l}\text { I can do this on } \\
\text { my own } \\
\text { without help }\end{array}$ \\
\hline \multirow[t]{2}{*}{ - Many ideas } & \multirow{2}{*}{$\begin{array}{l}\text { Pre- } \\
\text { intermediate }\end{array}$} & \multirow{2}{*}{$\begin{array}{l}\text { Combine } \\
\text { Describe } \\
\text { List } \\
\text { Classify }\end{array}$} & \multirow[t]{2}{*}{5 stars writing } & Level 2 \\
\hline & & & & $\begin{array}{l}\text { I can do this } \\
\text { with help or an } \\
\text { example }\end{array}$ \\
\hline \multirow[t]{2}{*}{ - One idea } & \multirow[t]{2}{*}{ Beginner } & \multirow{2}{*}{$\begin{array}{l}\text { Identify } \\
\text { Name } \\
\text { Recall } \\
\text { State }\end{array}$} & \multirow[t]{2}{*}{3 stars writing } & Level 1 \\
\hline & & & & $\begin{array}{l}\text { I am starting to } \\
\text { get it, but am } \\
\text { still confused }\end{array}$ \\
\hline \multirow[t]{2}{*}{ No idea } & \multirow[b]{2}{*}{ Beginner } & \multirow{2}{*}{$\begin{array}{l}\text { Follow simple } \\
\text { instruction }\end{array}$} & \multirow[b]{2}{*}{3 stars writing } & Level 0 \\
\hline & & & & $\begin{array}{l}\text { I still don't } \\
\text { understand }\end{array}$ \\
\hline
\end{tabular}

\section{Evaluation}

In order to evaluate the content validity of the Co-STAR Module, seven experts from teaching colleges, universities in Malaysia, School Improvement Specialist Coach and experienced English teacher with good experience in curriculum design, module development, assessment and English Language teaching were selected. According to Mullen (2003), the minimum amount of sample size is adequate with seven experts. Cronbach's Alpha showed the 
questionnaire composed with 20 items reach acceptable reliability, $\alpha=0.92$. Minimum Cronbach's Alpha value at $\alpha=0.800$ is acceptable for the overall reliability (K S Taber. 2018). The experts' reviews of the module content were generally positive with minor suggestions included:

1) The arrangement of writing activities at each level should be appropriate to the student level.

2) There should be a division of activities from low to high at each level in the module to ensure that the module can be used by every student with different ability in the classroom.

A total of 30 Year 5 low achiever learners (LAL) in a primary school with high population in Gombak have been selected for the pilot study. The term of LAL in this research referred to the low achievers who have been identified by their teachers as needing academic support, whether the students perform poorly on assessments or during classroom work. The participants were selected by using purposive technique because this method chose only participants who fulfilled the requirement and objective of the study. A set of questionnaires with 28 statements has been distributed and the frequencies and respond of the participants were recorded and analyze in mean and figures in order to present the responses in a more understandable way.

Table 2. Students' Responses to Statements of the Beginner, Intermediate and Advanced Level in the Co-STAR Module.

\begin{tabular}{|l|l|c|c|c|}
\hline \multirow{2}{*}{ No. } & \multicolumn{1}{|c|}{ Writing Levels } & Beginner & Intermediate & Advanced \\
\cline { 2 - 5 } & \multicolumn{1}{|c|}{ Statements } & $\mathrm{M}$ & $\mathrm{M}$ & $\mathrm{M}$ \\
\hline 1. & $\begin{array}{l}\text { I understand the description of the essay } \\
\text { writing activity based on the pictures } \\
\text { provided. }\end{array}$ & 4.13 & 4.17 & 4.40 \\
\hline 2. & I lnow and understand the words given. & 4.57 & 4.33 & 4.20 \\
\hline 3. & $\begin{array}{l}\text { I understand the picture and storyline given } \\
\text { clearly. }\end{array}$ & 4.63 & 4.30 & 4.43 \\
\hline 4. & $\begin{array}{l}\text { I can construct sentences based on pictures } \\
\text { given using my oun words. }\end{array}$ & 4.20 & 3.77 \\
\hline 5. & $\begin{array}{l}\text { I can construct and write sentences with } \\
\text { correct spelling and grammar. }\end{array}$ & 4.40 & 4.23 & 3.60 \\
\hline 6. & I can rewrite the sentences in paragraph. & 4.90 & 4.40 & 4.47 \\
\hline 7. & $\begin{array}{l}\text { I understand the rubric of self-assessment } \\
\text { and peer given. }\end{array}$ & 4.20 & 4.17 & 4.20 \\
\hline 8. & $\begin{array}{l}\text { I can make a self / peer assessment based on } \\
\text { the rubric given. }\end{array}$ & 4.17 & 4.13 & 3.97 \\
\hline 9. & $\begin{array}{l}\text { I understand the reflection of the writing } \\
\text { exercises. }\end{array}$ & 4.73 & 4.63 & 4.57 \\
\hline & Grand Mean & 4.467 & 4.285 & 4.178 \\
\hline
\end{tabular}

Below is the description of the responses to each statement in the questionnaire: 
- I understand the description of the essay writing activity based on the pictures provided. The students, responses to this statement are high as the mean score are 4.13, 4.17 and 4.40 for the three levels. This means that the students understand the instructions contained in the provided activities.

- I know and understand the words given. The students' responses to this statement are high as the mean score are 4.57, 4.33 and 4.20 for the three levels. This means that the students agree with this item.

- I understand the picture and storyline given clearly. The students' responses to this statement are high as the mean score are 4.63, 4.30 and 4.43 for the three levels. This means that the students can relate the visual stimulus provided with the writing exercises given.

- I can construct sentences based on pictures given using my own words. The students' responses to this statement are high but decreased from 4.20 at the intermediate level to 3.77 at the advanced level. It showed that they do not highly agree due to lack of vocabulary and proficiency in the language to write a story.

- I can construct and write sentences with correct spelling and grammar. The students' responses to this statement are high at beginner for 4.40 but decreased to 4.23 and 3.60 for intermediate and advanced levels. This relates to the inability of the students to acquire grammar skills especially choice of words and spelling which synonym with the LAL.

- I can rewrite the sentences in paragraph. The students' responses to this statement are high as the mean score are 4.90, 4.40 and 4.47 for the three levels. This means that the students agree to a great extent on this item.

- I understand the rubric of self-assessment and peer given. The students, responses to this statement are high as the mean score are 4.20,4.17 and 4.20 for the three levels. This means that the students understood on how to assess using the rubric and the new norm is acceptable.

- I can make a self / peer assessment based on the rubric given. The students, responses to this statement decreased as the mean score are 4.17, 4.13 and 3.97 for the three levels. This means that although the students understood the rubric (refer to item no.7) but in term of application; the advanced level rubric is more complicated which do not achieve their existing knowledge of the writing skills.

- I understand the reflection of the writing exercises. The students' responses to this statement are descending from 4.73 to 4.57 due to the level of difficulty of the exercises which relate with their writing ability to construct the essay themselves.

The findings of this questions showed that the major problems faced by the students are lack of vocabulary and grammar to complete the exercises given due to their low cognitive capability. In terms of applying the self and peer assessment of feedback, the results were quite encouraging and they can adapt the skills in a short time. It proves that the self-peer assessment process can be taught to the low achiever primary level if supported by opportunities to practice it regularly in an organized and supportive classroom environment. The SOLO taxonomy not only help students to clearly understand the item in their writing methodology but the same taxonomy can be used to score the items. Learners can take more control over their learning by clarification of the learning target and success criteria for teachers and learners themselves. 


\section{Conclusion}

The Co-STAR module which is based on self and peer assessment approach, SOLO Taxonomy and self-regulation model is hoped to equip the teachers with guidance and effective teaching tool towards a more organized teaching instructional and sources. Besides, contributing and bringing the gap for the implementation of self-assessment and peer feedback approaches in primary school, in order to enhance the LAL writing ability; promote language proficiency via several approaches to be employed by teachers in the classroom instruction and leads to pedagogical development in English writing in future. The implementation is also expected to build grit in students with low self-esteem to enhance their social interaction, more selfmotivated as well as promoting self-regulated learning (lifelong learning).

\section{Corresponding Author}

Prof. Madya Md. Nasir Bin Masran

Faculty of Human Development, Universiti Pendidikan Sultan Idris, 35900 Tanjong Malim, Perak, Malaysia.

Email:m.nasir@fpm.upsi.edu.my

\section{References}

Freij, M., \& Ahlin, L. (2014). Going forward with feedback: on autonomy and teacher feedback. In Text Analysis Symposium at Kristianstad University, April 2014 (pp. 42-58). Kristianstad University Press.

Hattie, J. (2013). Visible learning for teachers: Maximizing impact on learning. Routledge.

Kayani, M. A. H., Ajmal, M., \& Rahman, F. (2010). Teachers' perception regarding examination based on SOLO taxonomy. International Journal of Academic Research, 2(6), 208-211.

Majid, F. A. (2011). School-Based Assessment in Malaysian Schools: The Concerns of the English Teachers. Online Submission.

Mahmood, A., Ali, M. Q., \& Hussain, W. (2014). Understanding of Elementary School Teachers of 3rd World Country about Levels of SOLO Taxonomy. Mediterranean Journal of Social Sciences, 5(23), 1135.

Ministry of Education Malaysia. (2012). Malaysia Education Blueprint 2013-2015. Ministry of Education Malaysia.

Sardareh, S. A. (2018). Formative feedback in a Malaysian primary school ESL context. MOJES: Malaysian Online Journal of Educational Sciences, 4(1), 1-8.

Noah, S. M., \& Ahmad, J. (2005). Pembinaan modul: bagaimana membina modul latihan dan modul akademik. Serdang : Universiti Putra Malaysia.

Schreurs, J., \& Dumbraveanu, R. (2014). A shift from teacher centered to learner centered approach. International Journal of Engineering Pedagogy (iJEP), 4(3), 36-41.

Solomon, M. B. (2013). Teaching academic writing to graduate English as Second Language (ESL) students: the effects of instruction on student academic writing at the Adventist International Institute of Advanced Studies (AlIAS), Philippines (Doctoral dissertation).

Wertsch, J. V. (1985). Cultural, Communication, and Cognition: Vygotsky Perspectives. Cambridge University Press. 